\title{
A Study of Structural and Photoluminescence for Al-Doped CdO Thin Films
}

\author{
Bong Ju Lee and Jin Jeong \\ Department of Physics, Chosun University, Gwangju 501-759, Republic of Korea \\ Correspondence should be addressed to Jin Jeong; jeji@chosun.ac.kr
}

Received 24 January 2016; Revised 4 April 2016; Accepted 19 April 2016

Academic Editor: Eugen Culea

Copyright (C) 2016 B. J. Lee and J. Jeong. This is an open access article distributed under the Creative Commons Attribution License, which permits unrestricted use, distribution, and reproduction in any medium, provided the original work is properly cited.

\begin{abstract}
Al-doped $\mathrm{CdO}$ thin films were prepared by radio frequency magnetron sputtering at different deposition time and substrate temperature. X-ray diffraction showed that the changes in the intensities of the (200), (220), and (311) planes followed a similar trend with increase in deposition time. The surface of the thin film was examined by scanning electron microscopy. Grain sizes of Al-doped $\mathrm{CdO}$ thin films increased significantly with increasing deposition time. The film thicknesses were $0.09,0.12,0.20$, and $0.225 \mu \mathrm{m}$ for the deposition times of $1,2,3$, and $4 \mathrm{~h}$, respectively. The photoluminescence spectra of the Al-doped CdO thin films were measured at room temperature. The photoluminescence wavelength changed in the sequence, green, blue, green, and blue, with increasing deposition time, which indicates that blue light emitting films can be fabricated by adjusting the processing parameters.
\end{abstract}

\section{Introduction}

Thin films of transparent conducting oxides (TCO) are critical components of solar cells, gas sensors, and smart windows [1-4]. In radio frequency magnetron sputtering processes, the deposition parameters play a key role in determining the properties of thin films ( $\mathrm{CdO}$ in the present case) fabricated by using this technique. Several researchers have reported the effect of deposition parameters on the properties of $\mathrm{Sn}$-, $\mathrm{Ti}-$, $\mathrm{Al}$-, and In-doped $\mathrm{CdO}$ films prepared by radio frequency magnetron sputtering, pulsed laser deposition, and spray pyrolysis [5-9]. Al is a popular dopant in $\mathrm{ZnO}$ thin films; however, there have been very few reports on $\mathrm{Al}$-doped $\mathrm{CdO}$ thin films [10-12] and, so far, there are no detailed studies reporting the properties of $\mathrm{Al}$-doped $\mathrm{CdO}$ thin films on $\mathrm{Si}$ substrates that elucidate the relationship between the structure of the films as determined by X-ray diffraction (XRD) and the photoluminescence (PL) in this material. In this work, we have measured the PL and XRD of $\mathrm{Al}$-doped $\mathrm{CdO}$ thin films fabricated using the radio frequency magnetron sputtering technique at different substrate deposition temperatures and deposition times. We have also investigated the origin of the peaks in the PL spectra and their relation to the crystalline structure of the film surface.

\section{Experimental Details}

Al-doped CdO thin films were deposited on Si (001) by radio frequency (RF) magnetron sputtering. The sputtering targets were fabricated using polycrystalline $\mathrm{CdO}$ ceramic (5 N purity, Cerac Inc.) containing $2 \mathrm{wt} \% \mathrm{Al}_{2} \mathrm{O}_{3}$. The chamber was first reduced to a vacuum pressure of $<5 \times 10^{-5} \mathrm{~Pa}$ after which it was filled with a mixture of $\mathrm{N}_{2}$ and $\mathrm{O}_{2}$ using independent mass flow controllers to vary the oxygen partial pressure. The RF deposition substrate temperatures for sputtering $\mathrm{CdO}$ were $150^{\circ} \mathrm{C}, 250^{\circ} \mathrm{C}, 350^{\circ} \mathrm{C}$, and $450^{\circ} \mathrm{C}$, and the deposition times were $1 \mathrm{~h}, 2 \mathrm{~h}, 3 \mathrm{~h}$, and $4 \mathrm{~h}$, respectively. The $\mathrm{Al}$ target power was $100 \mathrm{~W}$ throughout the experiment. The target-substrate distance was maintained at $2.5 \mathrm{~cm}$. The various process parameters used in the film deposition are listed in Table 1.

The phase purity of the deposited films was examined by X-ray diffraction (XRD; Rigaku, Rix-2000) using a Ni filter and $\mathrm{Cu} \mathrm{K} \alpha$ radiation. The diffraction data were collected for $2 \theta$ values ranging from $20^{\circ}$ to $70^{\circ}$ with a step of $0.03^{\circ}$. 
TABLE 1: The deposition condition of Al-doped CdO thin films.

\begin{tabular}{lcccc}
\hline Sample & $\begin{array}{c}\text { Time } \\
(\mathrm{hr})\end{array}$ & $\begin{array}{c}\text { Temperature } \\
\left({ }^{\circ} \mathrm{C}\right)\end{array}$ & $\begin{array}{c}\text { Flow rate } \\
\mathrm{N}: \mathrm{O}(\mathrm{sccm})\end{array}$ & $\begin{array}{c}\text { Power } \\
(\mathrm{W})\end{array}$ \\
\hline S-1 & 1 & 150 & $10: 10$ & 100 \\
S-2 & 2 & 150 & $10: 10$ & 100 \\
S-3 & 3 & 150 & $10: 10$ & 100 \\
S-4 & 4 & 150 & $10: 10$ & 100 \\
S-5 & 1 & 250 & $10: 10$ & 100 \\
S-6 & 1 & 350 & $10: 10$ & 100 \\
S-7 & 1 & 450 & $10: 10$ & 100 \\
\hline
\end{tabular}

The morphology was confirmed by SEM (SEM; Hitachi, S4700, Japan). PL was measured using a $266 \mathrm{~nm}$ Ns : YAG laser (Spectron Physics, USA).

\section{Results and Discussion}

Figure 1 shows the XRD patterns of Al-doped CdO films for the groups of experiments S-1, S-2, S-3, and S-4. The observed peaks in the XRD correspond to polycrystalline CdO. Peaks associated to the (111), (200), (220), and (311) planes of the face centered cubic (fcc) structure are observed. The (111) peak intensities decreased with increasing deposition time, indicating that the crystallinity of the films deteriorated for increased deposition times. For the S-1, S-2, S-3, and S-4 films, the (200) plane corresponded to the highest intensity peak. In the fcc structure, the density of the atoms is the highest for the (200) plane which means that the surface energy of this plane is the lowest. When the deposition time was varied in the sequence, $1 \mathrm{~h}, 2 \mathrm{~h}, 3 \mathrm{~h}$, and $4 \mathrm{~h}$, the intensities of the X-ray diffraction peak for the (200) plane varied as follows: 1700, 900,1700 , and 1050, respectively. For the same deposition time increased, the intensities of the (220) plane were 500, 300,500 , and 300 and the intensities of the (311) plane were $250,150,220$, and 160 , respectively. Thus, the (200), (220), and (311) plane intensities showed the same trend for the groups of films S-1, S-2, S-3, and S-4.

Figure 2 shows the XRD patterns of Al-doped CdO films of groups S-5, S-6, and S-7. When the deposition temperature was increased from $250^{\circ} \mathrm{C}$ to $350^{\circ} \mathrm{C}$ and to $450^{\circ} \mathrm{C}$, the intensities of the XRD peak for the (200) plane were 475, 575, and 325 , respectively. For the same temperature variation, the intensities of the (220) plane were 100, 110, and 90, and the intensities for the (311) plane were 100, 110, and 75. These results show that a similar trend in the intensities of the (200), (220), and (311) planes is observed for the groups of films S-5, S-6, and S-7.

Figure 3 shows the SEM images of the surface and the cross sections of Al-doped $\mathrm{CdO}$ thin films from groups S-1, S-2, S-3, and S-4. The average size of the particles drastically increased from $25 \mathrm{~nm}$ to $75 \mathrm{~nm}(25,50,60$, and $75 \mathrm{~nm}$, resp., for the four groups). The thicknesses of the films increased with deposition time and were $0.09 \mu \mathrm{m}, 0.12 \mu \mathrm{m}, 0.20 \mu \mathrm{m}$, and $0.225 \mu \mathrm{m}$ for the deposition times of $1 \mathrm{~h}, 2 \mathrm{~h}, 3 \mathrm{~h}$, and $4 \mathrm{~h}$, respectively. With increasing deposition time, the surface of the films showed a tendency towards a bimodal morphology

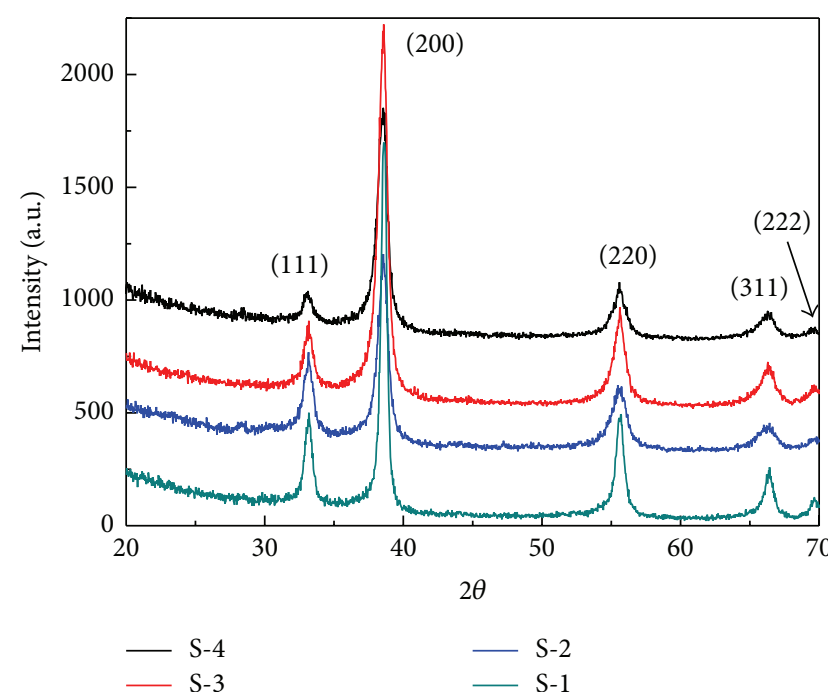

FIgURE 1: X-ray diffraction patterns of the Al-doped CdO films of S-1, S-2, S-3, and S-4 groups.

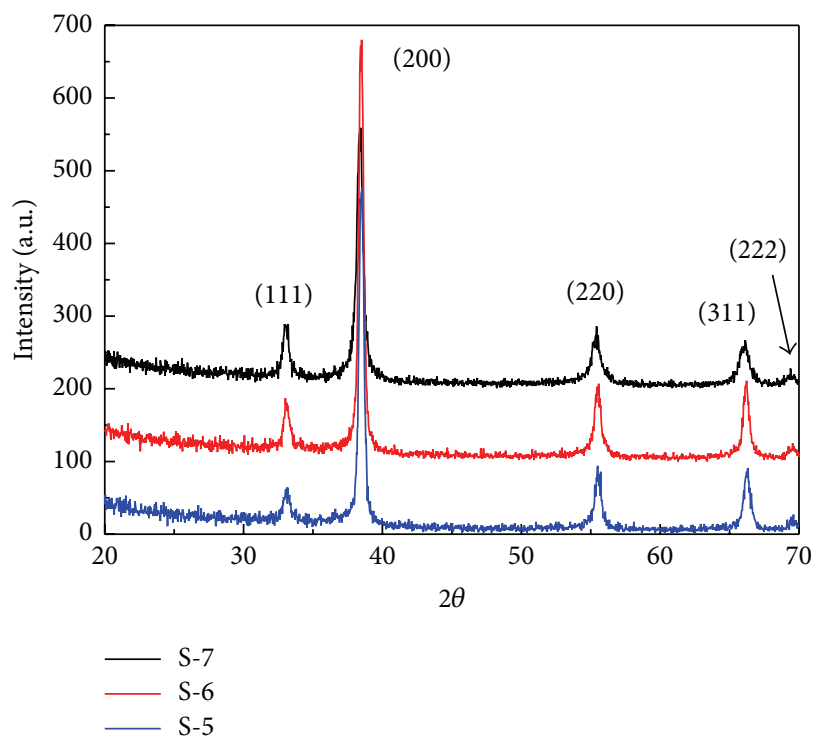

Figure 2: X-ray diffraction patterns of the Al-doped CdO films of S-5, S-6, and S-7 groups.

(see red and blue marks) and increased angular shape. The observed effect of the deposition condition on the surface morphology, microstructure, and defect concentration suggests that the grain growth in these films is bimodal $[13,14]$. The surface structure of a thin film is expected to vary due to grain growth during the deposition during which the interface will have an equilibrium shape. The relatively short deposition time generates a constant growth of particles; nonetheless, when the deposition time becomes more prolonged, the thin films density increases and new particles appear.

Figure 4 shows the surface and cross-sectional SEM images of $\mathrm{Al}$-doped $\mathrm{CdO}$ thin films. For the deposition temperatures of $250^{\circ} \mathrm{C}, 350^{\circ} \mathrm{C}$, and $450^{\circ} \mathrm{C}$, the corresponding mean particle diameters increased slightly and were $25 \mathrm{~nm}$, 


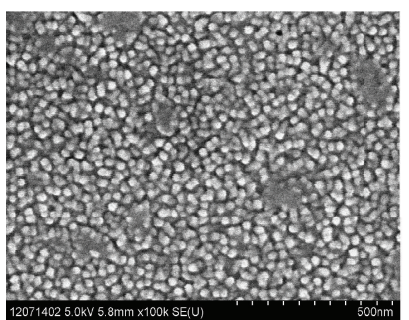

S-1

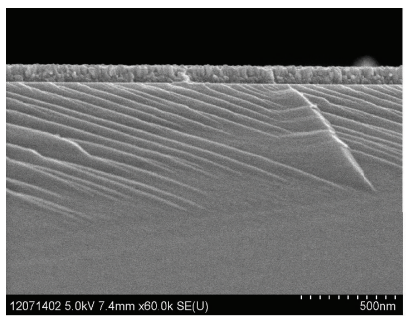

S-1

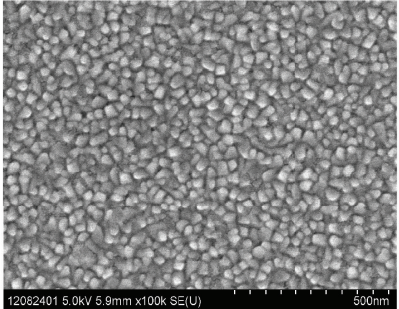

S-2

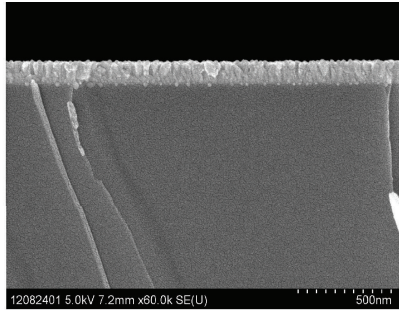

S-2

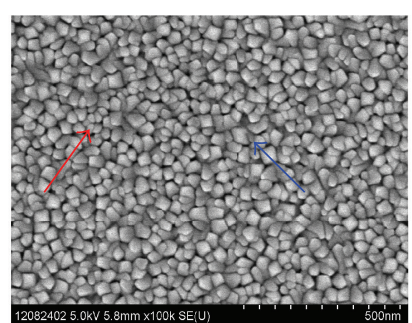

S-3

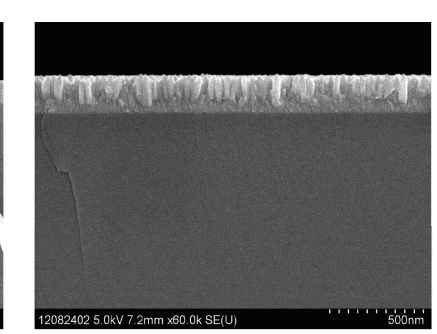

S-3

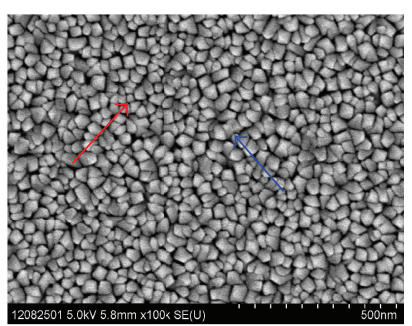

S-4

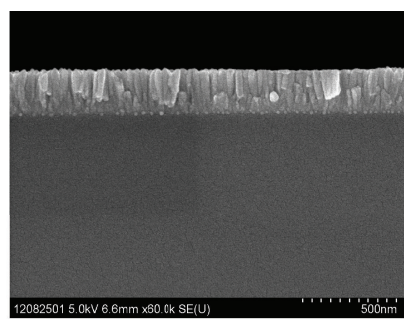

S-4

(b)

FIGURE 3: SEM images of the surface of the Al-doped CdO thin films: (a) S-1, S-2, S-3, and S-4 groups and cross-sectional SEM images; (b) S-1, S-2, S-3, and S-4 groups.

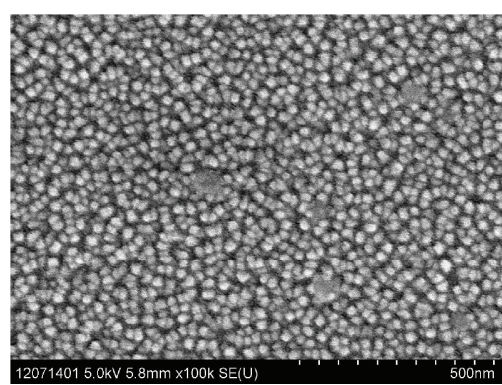

S-5

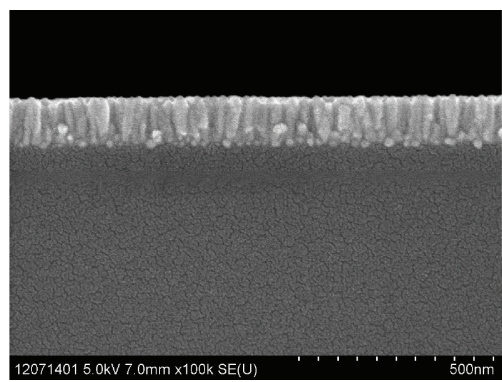

S-5

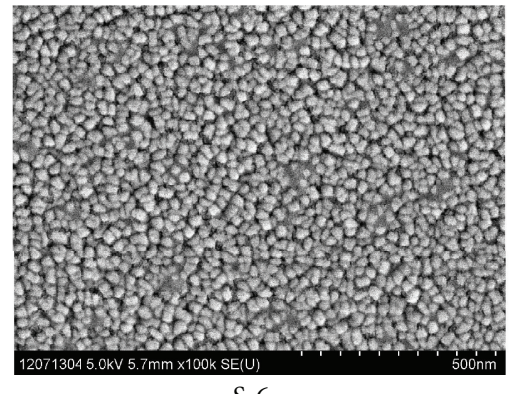

S-6

(a)

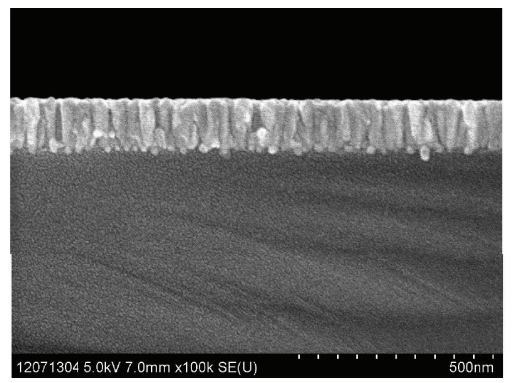

S-6

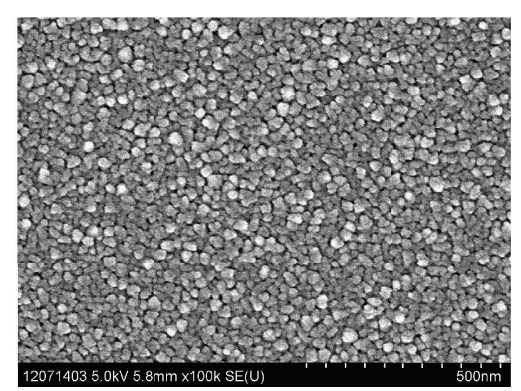

S-7

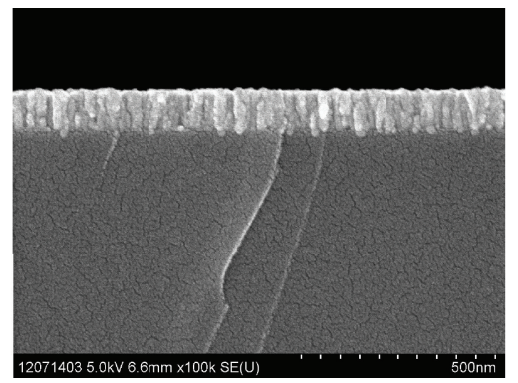

S-7

(b)

FIGURE 4: SEM images of the surface of the Al-doped CdO thin films: (a) S-5, S-6, and S-7 groups and cross-sectional SEM images; (b) S-5, S-6, and S-7 groups.

$25 \mathrm{~nm}$, and $35 \mathrm{~nm}$, respectively. The thickness of the film also changed; thicknesses of $125 \mathrm{~nm}, 120 \mathrm{~nm}$, and $110 \mathrm{~nm}$, respectively, were measured for the three deposition temperatures. When the deposition temperature was increased from $350^{\circ} \mathrm{C}$ to $450^{\circ} \mathrm{C}$, the mean particle diameter increased abruptly and, at the same time, the thickness of the films (cross section thickness) decreased.

When a crystal forms, first the nucleus is generated and then the adjacent atoms or ions stick to the nucleus in a preferential order determined by the energy level of the 


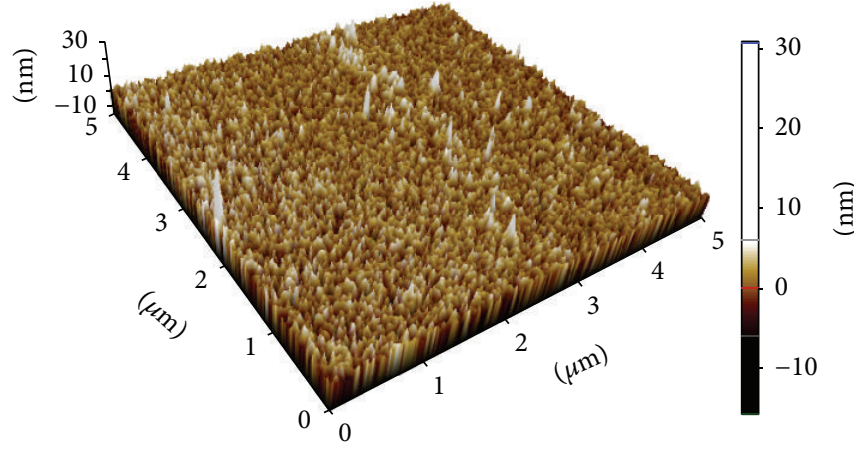

S-1

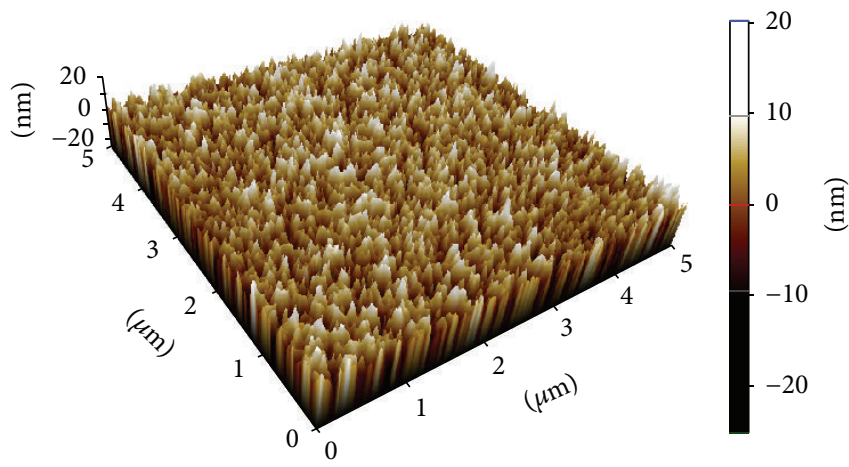

S-3

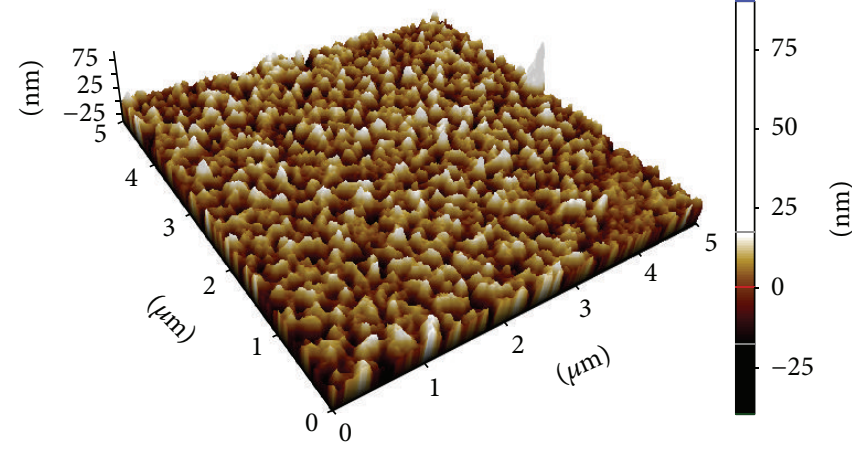

S-2

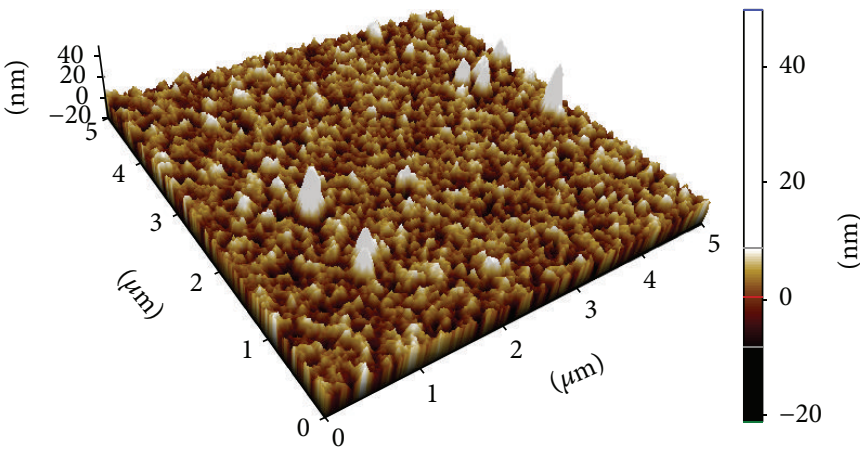

S-4

Figure 5: AFM images of the Al-doped CdO thin films of S-1, S-2, S-3, and S-4 groups.

lattice, forming a regular layer; on the other hand, if the growth occurs continuously, the particles may expand in two dimensions and overlapping of the particles may occur. This shows that there is a correlation between the decreased particle diameters and the increased cross section thickness.

Figure 5 shows the AFM images of the surfaces of Aldoped CdO thin films from groups S-1, S-2, S-3, and S-4. The root mean square (RMS) roughness was approximately $3.2 \mathrm{~nm}$ for S-1 within an area of $5 \times 5 \mu \mathrm{m}^{2}$. The AFM images confirm the results from SEM with respect to the effect of the deposition time for 3\% Al-doped CdO thin films indicating an agglomerated grain growth mode. The peak to valley roughness for the films grown at $1 \mathrm{~h}, 2 \mathrm{~h}, 3 \mathrm{~h}$, and $4 \mathrm{~h}$ was $21 \mathrm{~nm}, 63 \mathrm{~nm}, 30 \mathrm{~nm}$, and $25 \mathrm{~nm}$, respectively. Rounded protrusions with a lateral extent of the order of $21 \sim 25 \mathrm{~nm}$ were observed. According to the SEM images of groups S2, S3, and S4, the variation in thickness with deposition time is as follows: for deposition times of $2 \mathrm{~h}, 3 \mathrm{~h}$, and $4 \mathrm{~h}$, the thicknesses were $0.12 \mu \mathrm{m}, 0.20 \mu \mathrm{m}$, and $0.225 \mu \mathrm{m}$, respectively, and the corresponding RMS values were $9.1 \mathrm{~nm}$, $4.78 \mathrm{~nm}$, and $3.47 \mathrm{~nm}$, which means that as the cross section thickness increased, the roughness of the thin film decreased. This shows that if the cross section thickness increased, the particle density of the thin films decreased, which reduced the roughness of the thin films.

Figure 6 shows the AFM images of the surfaces of the Aldoped CdO thin films of groups S-5, S-6, and S-7. The RMS values for the three groups were $1.2 \mathrm{~nm}, 8.0 \mathrm{~nm}$, and $6.29 \mathrm{~nm}$, respectively. The surface crystallography was less ordered and hence the deposition temperature should be increased to decrease the film roughness.

Figure 7 shows the photoluminescence spectra of the Aldoped CdO thin films of groups S-1, S-2, S-3, and S-4. The results show that the PL intensities were $2.09 \times 10^{5}, 6.56 \times 10^{5}$, $18.2 \times 10^{5}$, and $7.6 \times 10^{5}$ for deposition times of $1 \mathrm{~h}, 2 \mathrm{~h}, 3 \mathrm{~h}$, and $4 \mathrm{~h}$, respectively. Analogously, the PL wavelength maximum changed in the order, green, blue, green, and blue, with increasing deposition time. The photoluminescence wavelength of S-1, S-2, S-3, and S-4 was $500 \mathrm{~nm}, 477 \mathrm{~nm}, 505 \mathrm{~nm}$, and $480 \mathrm{~nm}$, respectively. It is seen from Figure 1 that the intensities of the (200) plane for these samples were 1700, 900, 1700 , and 1050, respectively, and the peak intensities of the (220) plane were 500, 300, 500, and 300. The (311) plane also changed in the order, 250, 150, 220, and 160. As the deposition time increased and the thin film changed impurity and defect concentration, thus the photoluminescence properties of thin films are closely related to the crystallinity of the thin films. It is regarded that the growth direction of the thin films developing surface affects the location of photoluminescence. In addition, the surface morphology of the films plays an important role in determining the optical behavior of the Aldoped CdO thin films.

Figure 8 shows the PL spectra of the Al-doped CdO thin films surfaces for S-5, S-6, and S-7 groups. When the 

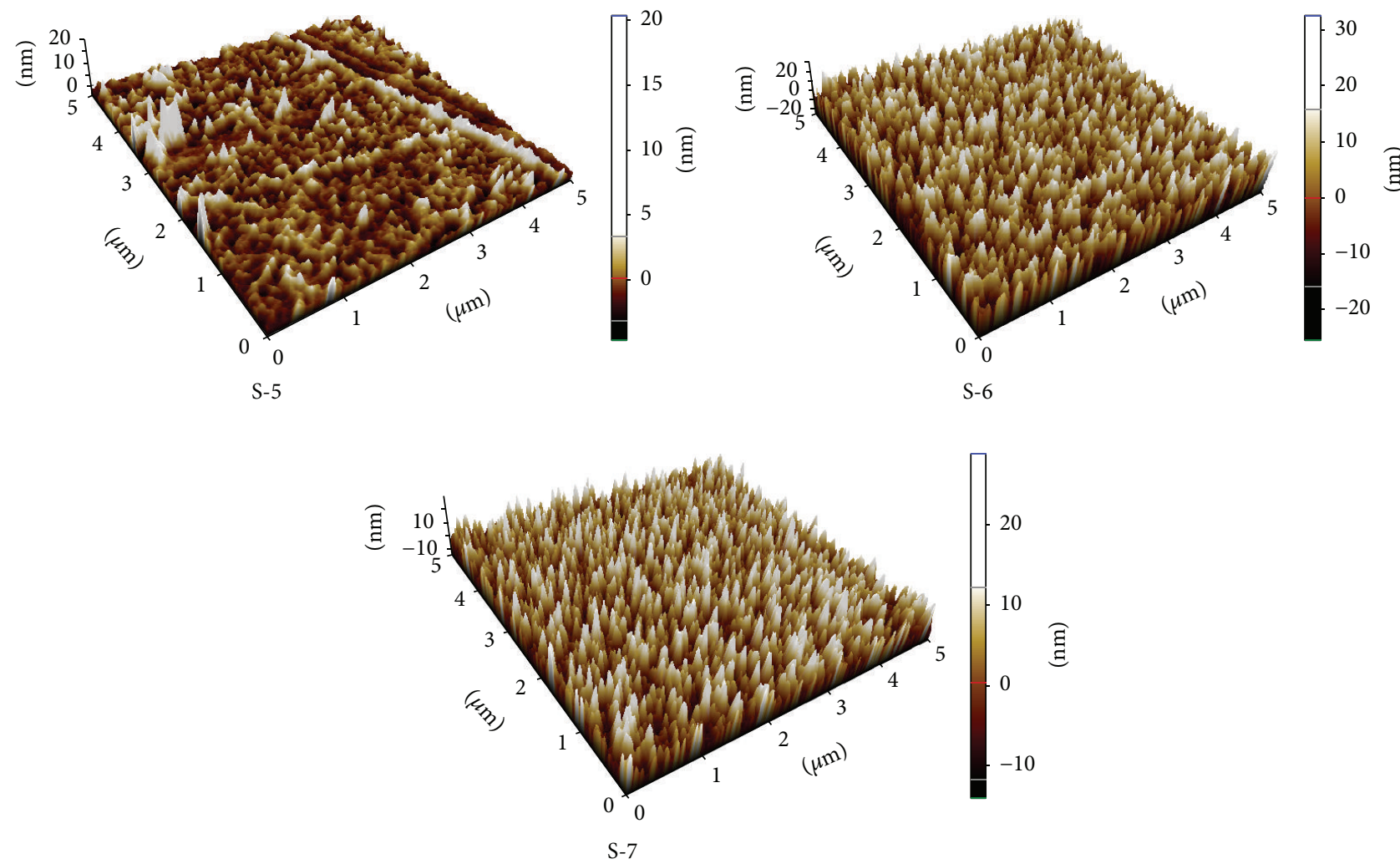

FIGURE 6: AFM image of the Al-doped CdO thin films of S-5, S-6, and S-7 groups.

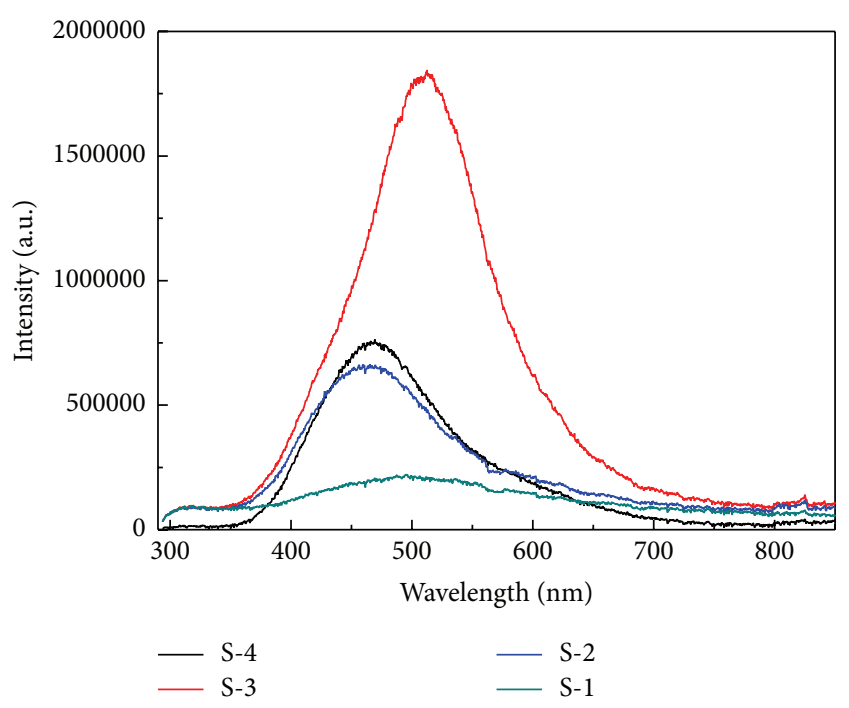

FIgURE 7: Photoluminescence spectra of the Al-doped CdO thin films surface of S-1, S-2, S-3, and S-4 groups.

deposition temperature is increased to $250^{\circ} \mathrm{C}, 350^{\circ} \mathrm{C}$, and $450^{\circ} \mathrm{C}$, the photoluminescence intensities decreased linearly to $17.5 \times 10^{5}, 10.0 \times 10^{5}$, and $3 \times 10^{5}$, respectively. As the temperature increases, the quantum confinement effect is higher and the PL intensity is decreased. Increasing the substrate temperature, the full width at half maximum of the photoluminescence emission peak increased. This suggests

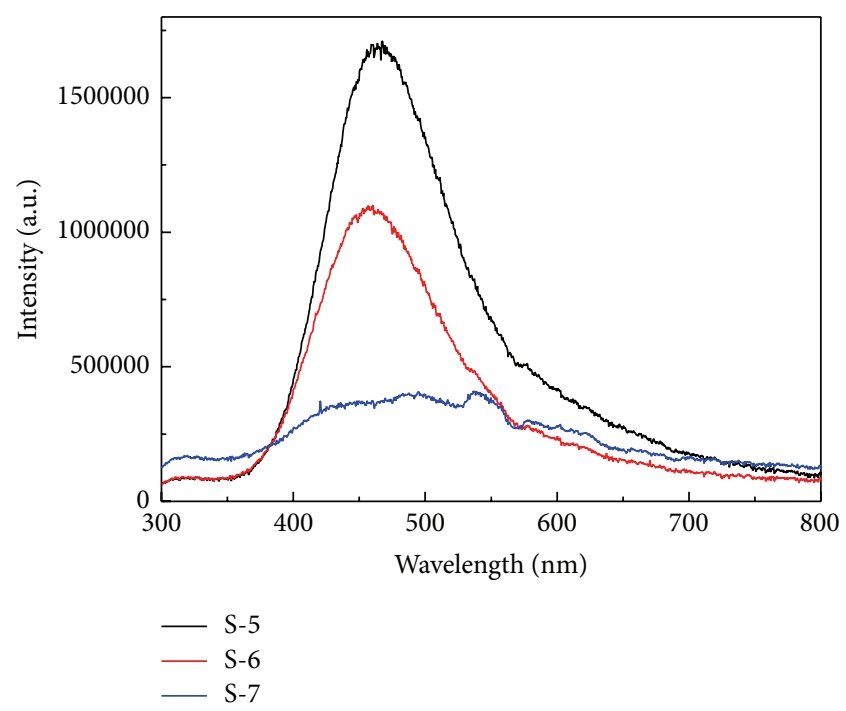

FIgure 8: Photoluminescence spectra of the Al-doped CdO thin films surface of S-5, S-6, and S-7 groups.

that due to enough thermal energy supplied by increase of growth temperature atoms move to stable sites and that impurities moved to grain boundary.

The photoluminescence wavelength of S-5, S-6, and S7 was $480 \mathrm{~nm}, 475 \mathrm{~nm}$, and $500 \mathrm{~nm}$, respectively. For S5, S6, and S7 thin films, in the X-ray diffraction analysis, the peak intensities of the (200) plane were 475, 575, and 
325 , respectively, for the three temperatures, the (220) peak intensity also changed to 100,110 , and 90 , and the (311) peak intensity changed to 100,110 , and 75 . This result indicated that the peak intensities of the (200), (220), and (311) plane were closely connected to the peak of location PL spectra. The substrate temperature increased, the crystal growth direction of the surface became disordered, and more surface area was exposed to air. Due to the change in growth direction, morphology of the thin films is changed and this affects the wavelength maximum in the PL spectra. As a result, the defect peak positions in the PL spectra are shifted.

\section{Conclusions}

The changes in the crystallography, morphology, and PL spectra of Al-doped $\mathrm{CdO}$ thin films are correlated with the deposition time and deposition temperature. The PL wavelength changes alternately in the sequence, green, blue, green, and blue, with increasing deposition time. As the deposition time increased, the thin film changed impurity, and defect concentration changed, the growth direction of the thin films developing surface affects the location of photoluminescence. With increase in deposition temperature, the quantum confinement is higher and the PL intensity is decreased. The energy shift might be affected by the bond length change with increasing substrate temperature.

\section{Competing Interests}

The authors declare that they have no competing interests.

\section{Acknowledgments}

This work was supported by research fund from Chosun University, 2015.

\section{References}

[1] H. Hosono, H. Ohta, M. Orita, K. Ueda, and M. Hirano, "Frontier of transparent conductive oxide thin films," Vacuum, vol. 66, no. 3-4, pp. 419-425, 2002.

[2] F. O. Adurodija, L. Semple, and R. Brüning, "Real-time in situ crystallization and electrical properties of pulsed laser deposited indium oxide thin films," Thin Solid Films, vol. 492, no. 1-2, pp. 153-157, 2005.

[3] C. H. Kwon, H.-K. Hong, D. H. Yun et al., "Thick-film zincoxide gas sensor for the control of lean air-to-fuel ratio in domestic combustion systems," Sensors and Actuators B: Chemical, vol. 25, no. 1-3, pp. 610-613, 1995.

[4] Y. Yang, Q. Huang, A. W. Metz et al., "Highly transparent and conductive $\mathrm{CdO}$ thin films as anodes for organic lightemitting diodes: film microstructure and morphology effects on performance," Society for Information Display, vol. 13, no. 5, pp. 383-387, 2005.

[5] J. A. A. Selvan, A. E. Delahoy, S. Guo, and Y.-M. Li, "A new light trapping TCO for nc-Si:H solar cells," Solar Energy Materials and Solar Cells, vol. 90, no. 18-19, pp. 3371-3376, 2006.

[6] A. A. Dakhel, "Bandgap narrowing in $\mathrm{CdO}$ doped with europium," Optical Materials, vol. 31, no. 4, pp. 691-695, 2009.

[7] R. K. Gupta, K. Ghosh, R. Patel, S. R. Mishra, and P. K. Kahol, "Preparation and characterization of highly conducting and transparent $\mathrm{Al}$ doped $\mathrm{CdO}$ thin films by pulsed laser deposition," Current Applied Physics, vol. 9, no. 3, pp. 673-677, 2009.

[8] M. K. R. Khan, M. A. Rahman, M. Shahjahan et al., "Effect of Al-doping on optical and electrical properties of spray pyrolytic nano-crystalline CdO thin films," Current Applied Physics, vol. 10, no. 3, pp. 790-796, 2010.

[9] B. Saha, R. Thapa, and K. K. Chattopadhyay, "Bandgap widening in highly conducting $\mathrm{CdO}$ thin film by $\mathrm{Ti}$ incorporation through radio frequency magnetron sputtering technique," Solid State Communications, vol. 145, no. 1-2, pp. 33-37, 2008.

[10] K. R. Murali, A. Kalaivanan, S. Perumal, and N. Neelakanda Pillai, "Sol-gel dip coated CdO:Al films," Journal of Alloys and Compounds, vol. 503, no. 2, pp. 350-353, 2010.

[11] S. Iican, M. Caglar, Y. Caglar, and F. Yakuphanoglu, "CdO:Al films deposited by sol-gel process: a study on their structural and optical properties," Optoelectronics and Advanced Materials: Rapid Communications, vol. 3, pp. 135-140, 2009.

[12] E. G. Birgin, I. Chambouleyron, and J. M. Martínez, "Estimation of the optical constants and the thickness of thin films using unconstrained optimization," Journal of Computational Physics, vol. 151, no. 2, pp. 862-880, 1999.

[13] S. Min and J. Jeong, "A study of atypical grain growth properties for $\mathrm{SnO}_{2}$ thin films," Materials Science in Semiconductor Processing, vol. 16, no. 5, pp. 1267-1270, 2013.

[14] J. Jeong, D.-S. Na, B.-J. Lee, H.-J. Song, and H.-G. Kim, "Effects of interface between $\mathrm{SnO}_{2}$ thin film and Si substrate on growth time," Current Applied Physics, vol. 12, no. 1, pp. 303-306, 2012. 

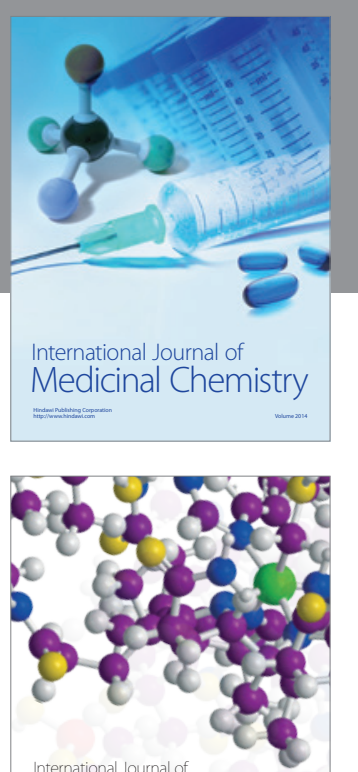

Carbohydrate Chemistry

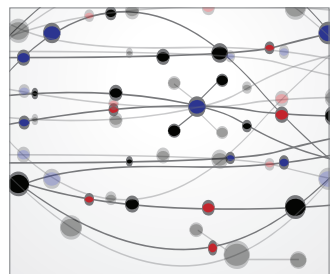

The Scientific World Journal
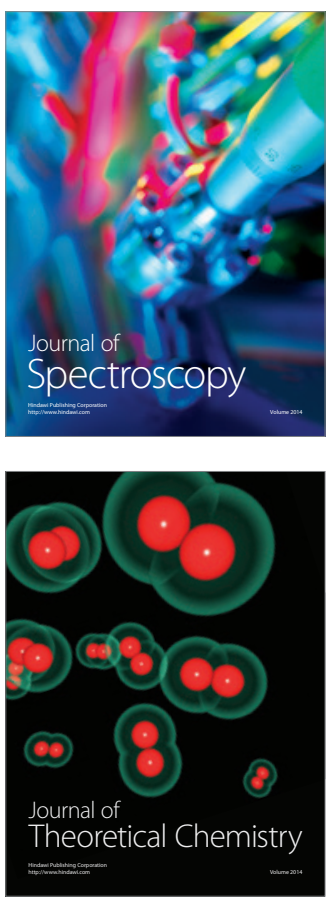
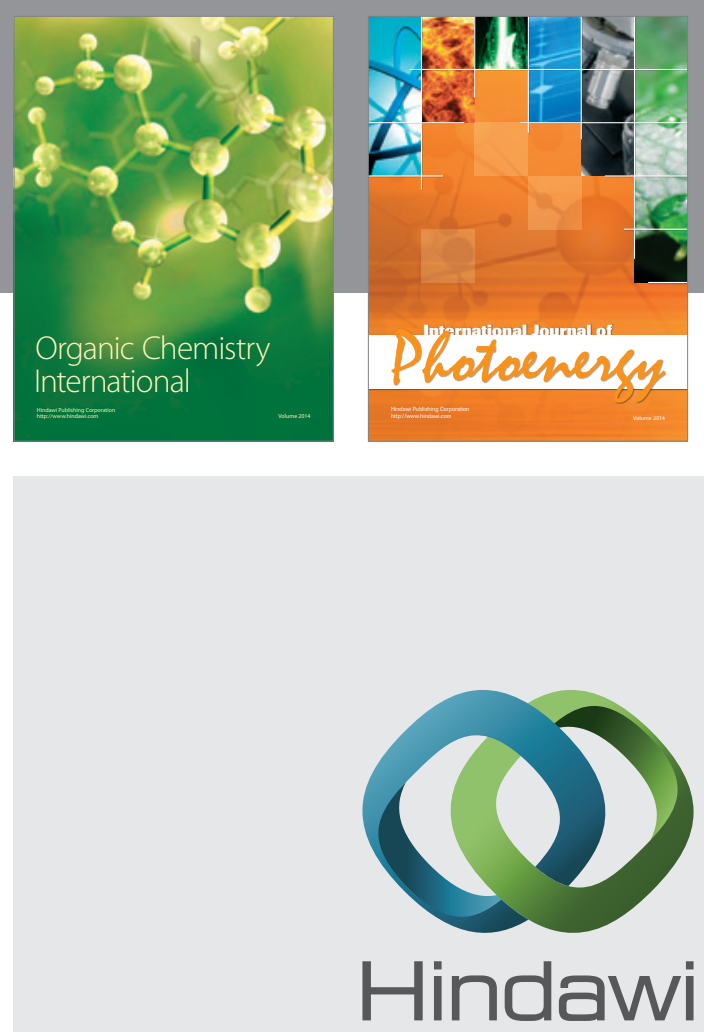

Submit your manuscripts at

http://www.hindawi.com

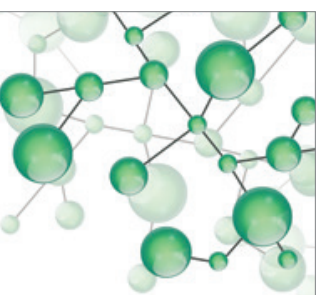

International Journal of

Inorganic Chemistry

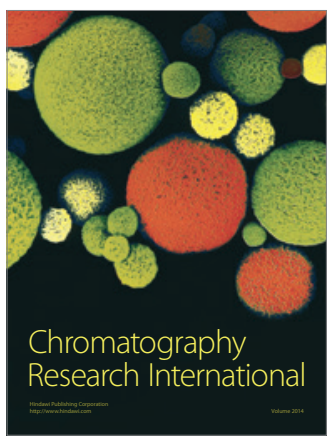

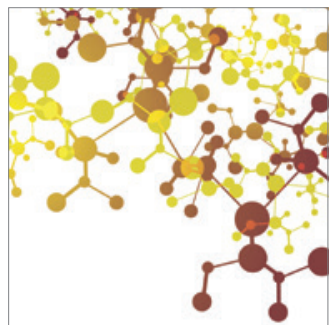

Applied Chemistry
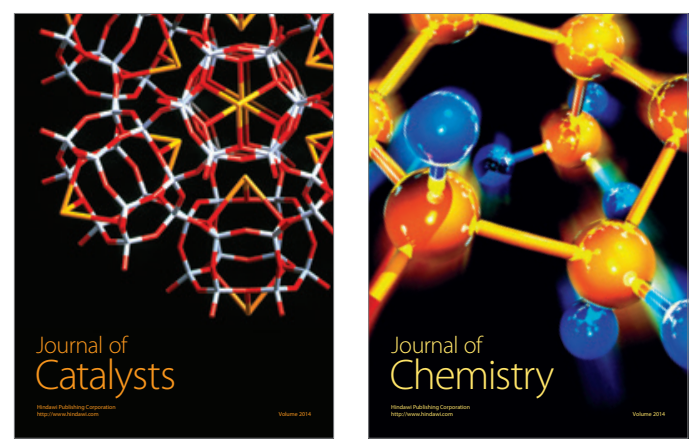
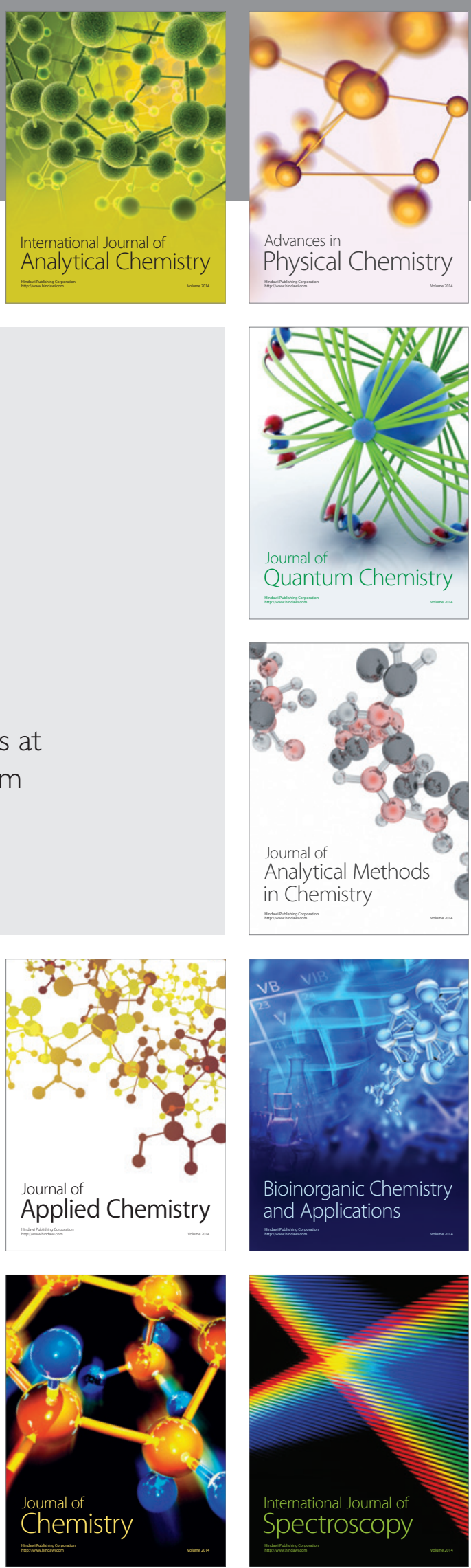